\title{
CULTURA NA SALA DE AULA: INVESTIGANDO TEMÁTICAS PARA O DESENVOLVIMENTO DE ATIVIDADES DE MODELAGEM MATEMÁTICA
}

\author{
Andressa Franco Vargas ${ }^{1}$; Eleni Bisognin²
}

\section{RESUMO}

O presente trabalho tem por objetivo apresentar um levantamento de temáticas com um grupo de estudantes de uma escola do campo, a fim de identificar possíveis contextos que podem ser discutidos em sala de aula por meio de atividades de Modelagem Matemática. Para o levantamento das temáticas, organizamos dois instrumentos de coleta de dados: a) Roda de conversa; b) Chuva de Ideias, para aplicação com estudantes do 9o ano de uma escola do campo da região oeste do Rio Grande do Sul. Ao analisar os dados, entendemos que a cultura da Agricultura, da Pecuária e da Pesca possuem forte presença na comunidade, fazendo parte da rotina das famílias. Sendo assim, destacamos que a vivência é a maior experiência que um indivíduo pode ter sobre um contexto, é por isso que, a discussão de temáticas que partem dos estudantes, pode auxiliar estes a entender o seu meio e modificá-lo.

Palavras-chave: Educação do Campo, Educação Básica, Contexto Escolar.

Eixo Temático: Educação, Cultura e Comunicação (ECC).

\section{INTRODUÇÃO}

$\mathrm{Na}$ atualidade, as pesquisas relacionadas a aspectos culturais vêm ganhando força nas mais diversas esferas sociais, como na educação, na política e no cotidiano, valorizando e impulsionando a compreensão da cultura como uma peçachave para o entendimento e reflexão do mundo contemporâneo (NETO, 2003).

Estes aspectos culturais, por sua vez, consistem em elementos provenientes da cultura de um povo ou comunidade e, abraçam questões como conhecimento, crença, arte, costumes e todas as capacidades e hábitos adquiridos pelos sujeitos de um grupo social (THOMPSON, 2009).

Entendendo a escola como um destes espaços sociais, vê-se a necessidade

\footnotetext{
${ }^{1}$ Andressa Franco Vargas - Universidade Franciscana - andressavargas1@yahoo.com.br

2 Eleni Bisognin - Universidade Franciscana - eleni@ufn.edu.br
} 
de discutir e promover interações dos estudantes entre si e com o meio em que se vive, uma vez que por meio destas trocas é que estes estudantes se tornam sociais, históricos e principalmente, produtores de cultura (SILVEIRA, NADER e DIAS, 2007).

Estas questões culturais se apresentam de forma mais evidente quando pensamos em escolas do campo, onde a culturalidade é um dos pilares que baseiam o ensino nestas instituições. Isto, pois, conforme apontam as Diretrizes Complementares da Educação Básica do Campo, existe uma necessidade da adaptação de metodologias às características de cada comunidade onde estas escolas estão localizadas, prezando a garantia de respeito as diferenças, o estilo da vida e, as atividades econômicas (BRASIL, 2008).

Esta diversidade cultural presente nas escolas do campo se justifica pois a modalidade da Educação do Campo, surge com o intuito de ofertar Ensino Básico de qualidade para regiões rurais, englobando culturas "pesqueiros, caiçaras, ribeirinhos e extrativistas. O campo, nesse sentido, mais do que um perímetro não-urbano, é um campo de possibilidades" (BRASIL, 2013, p. 267).

Neste sentido, entende-se que estas escolas devem abraçar as diversidades, fazendo com que a sala de aula do campo seja um campo de possibilidades para a discussão da realidade por meio da ciência.

É por esta justificativa, que podemos apontar a Modelagem Matemática como uma metodologia de ensino que envolve e compreende estas necessidades, justamente pelo fato de que na concepção da Educação Matemática, a Modelagem preza por relacionar conhecimentos matemáticos com a realidade dos estudantes, favorecendo a participação do sujeito no seu próprio processo de aprendizagem, admitindo assim, significados para o seu meio tendo seus próprios vínculos sociais como ponto de partida (CALDEIRA, 2009).

Blum (1995, p.18) a define, a Modelagem "[...] como sendo um processo de construção de modelos que transforma uma situação real em uma situação Matemática [...]". Sendo assim, a metodologia pode ser uma alternativa para auxiliar na formação do estudante como um cidadão que entende seu contexto e por isso, é 
capaz de explorar, indagar e resolver problemas que envolvem fenômenos que ocorrem em seu cotidiano.

Devido a estas razões, o presente trabalho ter por objetivo, apresentar um levantamento de temáticas com um grupo de estudantes de uma escola do campo, a fim de identificar possíveis contextos que podem ser discutidos em sala de aula por meio de atividades de Modelagem Matemática.

Nos itens abaixo, apresentamos a elaboração e o desenvolvimento destas intervenções no ambiente escolar, bem como os resutlados e possíveis reflexões obtidos após a aplicação juntamente aos estudantes.

\section{METODOLOGIA}

A pesquisa aqui apresentada foi desenvolvida no segundo semestre de 2019, tendo como público-alvo, nove estudantes do 9ำ ano de uma escola do campo da região oeste do Rio Grande do Sul. Para o levantamento das temáticas mais significativas para a comunidade escolar e região, organizamos dois instrumentos de coleta de dados.

O primeiro consiste em uma série de questões norteadoras para uma roda de conversa com os estudantes, são elas: a) Quais são as práticas mais comuns em sua vida do campo?; b) Quais as principais práticas realizadas por sua família no campo?; c) O que você mais gosta de estudar em Matemática?; d) Você consegue observar que a Matemática está presente em alguma atividade que você realiza? Qual?; e) Você sente falta de trabalhar em sala de aula assuntos que fazem parte de sua rotina?; e f) Em quais conteúdos de Matemática você apresenta mais dificuldades?

As questões para este momento de diálogo versam sobre as práticas desenvolvidas na comunidade, a rotina dos estudantes, a presença da Matemática nestas ações e a relações destes sujeitos com a disciplina.

Já para o segundo momento de intervenção, organizamos uma atividade nomeada "Chuva de Ideias", que consiste em uma evocação de palavras sobre a frase "A Matemática no Campo", onde os sujeitos puderam ressaltar o que vem a sua mente quando pensa na relação da Matemática com o contexto do campo. 
Assim, foi entregue aos estudantes em formato de uma nuvem onde com a frase "a Matemática do Campo", conforme ilustra a figura 01, disposta abaixo.

Figura 01 - Nuvem da Palavras

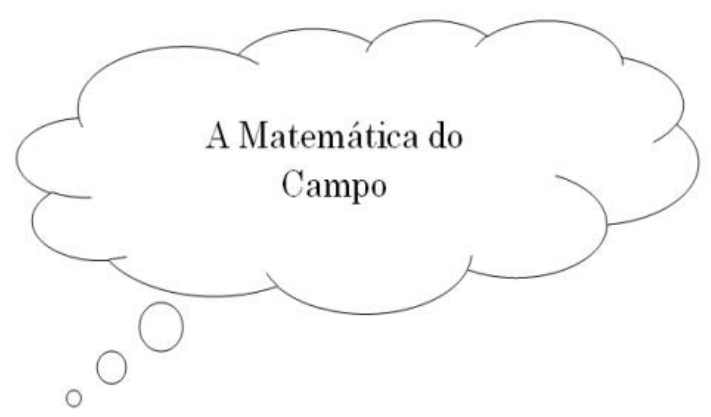

Fonte: Próprias autoras

Através destes dois instrumentos os estudantes tiveram a oportunidade de refletir sobre o seu próprio meio, apontando temas que fazem parte de sua rotina e que podem ser discutidos em sala de aula, ressaltando a importância da culturalidade como um elemento norteador para a significação de conhecimentos científicos.

Como forma de análise dos dados obtidos, organizamos para cada uma das questões, categorias de análise, seguindo a concepção de Bardin (2010), considerando categorias para um entendimento teórico e interpretativo das informações coletadas. Já para a aplicação destes instrumentos organizamos dois momentos de intervenção, em dias distintos durante as aulas de Matemática, estabelecendo um diálogo com os sujeitos envolvidos.

\section{RESULTADOS E DISCUSSÕES}

A fim de organizar os dados obtidos após as aplicações, analisamos os momentos separadamente. Com relação ao primeiro momento que se tratava da roda de conversa com os estudantes, analisamos as respostas, indicando categorias de análise.

A primeira questão "Quais são as práticas mais comuns em sua vida no campo?" fazia relação as práticas mais comuns na vida dos estudantes no campo A tabela 01, disposta abaixo, sintetiza as respostas obtidas para este questionamento, sendo elencadas três categorias. 
Tabela 01 - Análise das respostas referentes a questão norteadora 01

\begin{tabular}{c|c} 
Categorias & Número de respostas \\
\hline Colheita de Legumes & 3 \\
\hline Contagem de Gado e Ovelhas & 5 \\
\hline Pesca & 1
\end{tabular}

Fonte: Dados da Pesquisa

Ao analisar as respostas fica evidenciada a presença da agricultura e da pecuária, práticas de grande importância no município onde a escola está localizada. Exemplos como a contagem do gado, a medição de quadras de campo, o manejo e cuidado com os animais e o cultivo de hortaliças foram destacados por se tratar de ações cotidianas básicas nas fazendas e propriedades onde os estudantes residem.

Além disso, um dos estudantes citou a pesca, pois esta prática é uma das fontes de renda de sua família. O estudante $\mathrm{C}$, apontou que para pescar é necessário saber e utilizar Matemática, pois esta é utilizada desde a medição de linhas de pescar até o cálculo de distâncias.

Com relação ao segundo questionamento, "quais as principais práticas realizadas por sua família no campo?", os estudantes puderam relatar experiência de sua rotina e de sua família. Sobre os resposta para esta questão norteadora construímos quatro categorias, conforme descreve a tabela abaixo (Tabela 02).

Tabela 02 - Análise das respostas referentes a questão norteadora 02

\begin{tabular}{c|c} 
Categorias & Número de respostas \\
\hline Plantação de Legumes e Frutas & 3 \\
\hline $\begin{array}{c}\text { Criação e Manejo de Gado, Ovelhas } \\
\text { e Galinhas }\end{array}$ & 3 \\
\hline Construção de Cercas & 2 \\
\hline Preparo de terras para plantio & 1
\end{tabular}

Fonte: Dados da Pesquisa

Sobre este segundo questionamento podemos apontar a diversidade de prática que vão desde a plantação de legumes e frutas para venda e consumo até a construção de cercas para a divisão de campos e o cuidado com os animais. 
Os sujeitos ressaltaram nesta etapa que é muito comum "o aprender" com seus familiares sobre estas práticas, como se a cultura fosse repassada de geração em geração, sendo aprimorada com o passar do tempo.

Sobre o terceiro questionamento norteador, começamos a indagar a relação dos estudantes com a Matemática, fazendo com que expressassem suas opiniões com relação a conteúdos trabalhados na disciplina.

Desta forma, perguntamos "O que você mais gosta de estudar na disciplina de Matemática?" instigando os estudantes a pensar sobre o que já aprenderam e discutiram na disciplina em sua trajetória escolar. A tabela abaixo (Tabela 03) destaca os comentários dos estudantes, organizados em cinco categorias, conforme os conceitos citados.

Tabela 03 - Análise das respostas referentes a questão norteadora $03^{3}$

\begin{tabular}{c|c} 
Categorias & Número de respostas \\
\hline Equações do 1º grau & 1 \\
\hline Operações básicas & 6 \\
\hline Área e Perímetro & 3 \\
\hline $\begin{array}{c}\text { Mínimo Múltiplo Comum e Máximo } \\
\text { Divisor Comum }\end{array}$ & 2 \\
\hline Monômios e Polinômios & 5
\end{tabular}

Fonte: Dados da Pesquisa

Observando as respostas em destaque se percebe a variedade de conteúdos citados, desde questões voltadas para a Álgebra, como monômios, polinômios e equações, até operações básicas da Matemática como multiplicação, divisão, subtração e adição.

A ênfase com relação aos tópicos de Álgebra pode se justificar, uma vez que os estudantes estavam estudando conceitos de monômios e polinômios com a professora regente e em momento anterior, haviam estudado Geometria, explorando conceitos de área e perímetro de polígonos regulares.

Tendo em vista os conceitos matemáticos destacados pelos estudantes, partimos para a questão 04, questionando se é "possível observar que a Matemática

\footnotetext{
${ }^{3}$ Neste momento os estudantes puderam apontar mais de um conceito, expondo suas afinidades com a disciplina.
} 
esta presente em alguma atividade que você realiza? Qual?". Oportunizando um espaço para debate das relações da disciplina com o contexto do campo. A tabela abaixo (Tabela 04) ilustra as categorias organizadas após a análise dos dados obtidos.

Tabela 04 - Análise das respostas referentes a questão norteadora 04

\begin{tabular}{c|c} 
Categorias & Número de respostas \\
\hline Não & 4 \\
\hline Sim, na medição dos campos & 1 \\
\hline Sim, na contagem da ração dos \\
animais & 1 \\
\hline Sim, na economia da família & 2 \\
\hline Sim, na venda de pães e doces & 1
\end{tabular}

Fonte: Dados da Pesquisa

Com relação a este questionamento fica evidente que os estudantes, em grande parte, não conseguem relacionar a Matemática vista na escola com suas ações cotidianas, uma vez que quatro dos nove sujeitos apontaram que não conseguem identificar a presenta de conceitos matemáticos na sua rotina.

As demais categorias elencadas fazem juz a cultura da região, pois desde cedo a relação com o campo, com a artesanato e com a culinária são valorizados, na comunidade. Pensando nisso, os sujeitos destacaram que seria interessante que estes valores e práticas fossem discutidos e interpretados em forma de números, letras, poemas, mapas e textos.

Isto, se justifica pelo fato de que a valorização dos conhecimetos prévios dos estudantes é um fator que serve de âncora para a construção de novos conhecimentos e significados mais elaboradas frente as conceitos e situações, sejam elas de cunho científico ou popular (AUSUBEL, 1982).

Esta necessidade de contextualização perpassa por algumas questões que cercam o ensino de Matemática como, por exemplo: "Por que eu preciso aprender isso?" ou "No que eu vou usar a Matemática?". Sendo assim, se entende que ao descrever um contexto ou explicar uma situação real, se evidencia o significado do 
porquê e para que estudar estes conceitos, frisando o papel da escola neste processo.

É com o intuito de investigar o interesse dos estudantes por atividades de sala desta natureza que conversamos sobre os mesmos sentiam "falta de trabalhar em sala de aula assuntos que fazem parte de sua rotina?". Ao analisar as respostas obtidas, foi possível a organização de três categorias apresentadas na tabela abaixo (Tabela 5).

Tabela 05 - Análise das respostas referentes a questão norteadora 05

\begin{tabular}{c|c} 
Categorias & Número de respostas \\
\hline Não & 2 \\
\hline $\begin{array}{c}\text { Sim, pois seria mais interativo e fácil } \\
\text { prática }\end{array}$ & 4 \\
\hline $\begin{array}{l}\text { Sim, pois seria possível aprender na } \\
\text { prica }\end{array}$ & 3 \\
\end{tabular}

Fonte: Dados da Pesquisa

Com base nas respostas dos estudantes, entende-se que talvez, para alguns, a mudança na dinâmica da sala de aula não seja necessária, porém, para uma quantidade significativa de estudantes esta mudança seja uma peça-chave para um ensino mais dinâmico e que preconize a culturalidade como tema de debate para a construção de conhecimentos científicos em sala de aula.

Outro ponto relevante é a questão da aprendizagem na prática, práticas estas destacadas nos questionamentos já citados acima, na concepção dos alunos a lida no campo e suas ramificações são elementos que poderiam tornar o ensino mais flexível, sendo possível a discussão de questões como plantações, criação de animais, a agricultura familiar e entre tantos outros temas.

Pensando na questão da aprendizagem, migramos para o sexto e último questionamento norteador da conversa com os estudantes, identificando "quais conteúdos da disciplina de Matemática você apresenta mais dificuldades?". O resumo das respostas obtidas está organizado na tabela abaixo (Tabela 06). 
Tabela 06 - Análise das respostas referentes a questão norteadora 06

\begin{tabular}{c|c} 
Categorias & Número de respostas \\
\hline Expressões Algébricas & 3 \\
\hline Polinômios & 1 \\
\hline $\begin{array}{c}\text { Problemas envolvendo conteúdos } \\
\text { diversos }\end{array}$ & 2 \\
\hline Regras de Sinais & 2 \\
\hline Radiciação & 1
\end{tabular}

Fonte: Dados da Pesquisa

Ao analisar as respostas obtidas, entende-se que a maior dificuldade apresentada pelos estudantes está voltada para algébricas, o que segundo os sujeitos implica em outros obstáculos, como problemas com operações e sinais de subtração.

A professora regente da turma participou da conversa e compreendeu a fala destes estudantes, uma vez que pôde identificar algumas lacunas com relação a conceitos trabalhados em anos anteriores ( $7^{\circ}$ e $8^{0}$ anos), podendo repensar estratégias para discussões dos conceitos.

Após a análise de todos os questionamentos, entendemos que se destacam três temas base, são eles: a) Agricultura; b) Pecuária; c) Pesca. A agricultura foi enfatizada com as questões da plantação de legumes, verduras, frutas e por estar fortemente ligada a questão da economia familiar.

Para o tema da Agricultura, pensamos que as possíveis potencialidades para a sua inserção em sala de aula podem partir do fato de que a cidade de X (município onde a escola está localizada) conta com uma vasta produção de arroz, juntamente com a soja, o milho e o trigo, e grande parte da produção se deve ao trabalho de habitantes da zona rural.

Devido a esta questão do cultivo, a conexão com a Matemática pode ser se dar pelos seguintes aspectos: lucro e prejuízo, plantações (espaço e forma), tempo de produção, armazenamento, impactos sociais e ambientais. 
Com relação ao tema da Pecuária, pode ser explorada a questão do rebanho de gado, ovelhas, suínos, galinhas e, ainda a produção de pão e doces, uma vez que dependem de ovos, leite etc.

E para isso, é preciso que haja produção familiar para auxiliar na subsistência dessas famílias. Pensando neste contexto, entende-se que é possível explorar questões relacionadas a conceitos geométricos, como área, perímetro e medidas, tendo como ponto de partida a medição dos campos e, a distribuição de animais nestes espaços.

A última temática identificada nas respostas foi a Pesca, pois a escola está localizada em uma região com uma vasta quantidade de açudes e barragens, o que faz com que essa prática esteja ligada ao cotidiano dos alunos. Assim, questões relacionadas a estatística podem ser discutidas, como média, moda, mediana, construção de gráficos e tabelas.

Após destacar estas temáticas, partimos para a segunda atividade, a Chuva de Ideias, com o intuito de destacar as ideias dos estudantes sobre a relação da Matemática com o campo. Ao apresentar aos estudantes a nuvem (disposta na figura 02), foi possível organizar uma síntese das respostas.

Figura 02 - Síntese dos resultados referentes a Chuva de Ideias

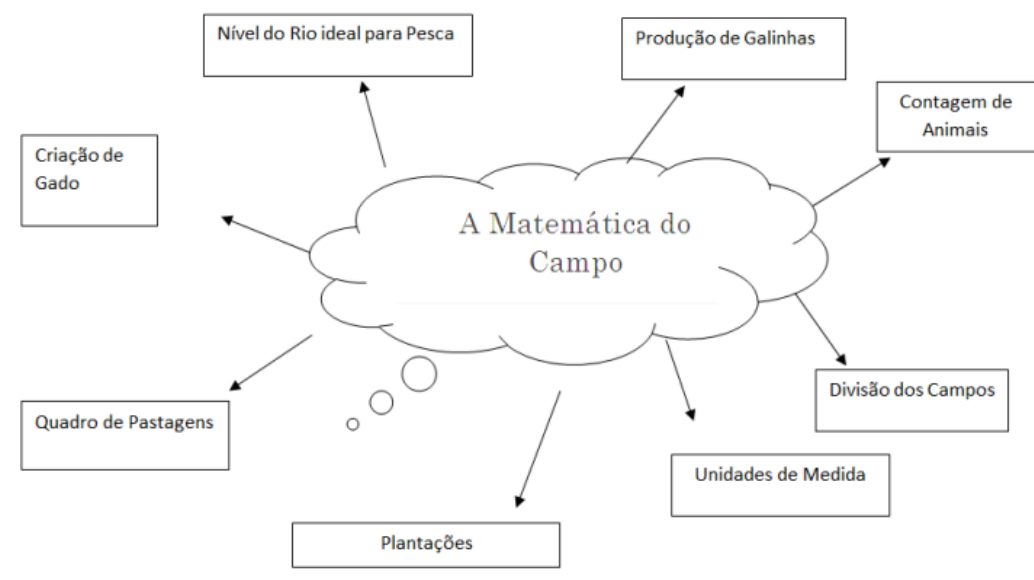

Fonte: Dados da Pesquisa

Nesta atividade, foi possível observar algumas situações envolvendo os temas já citados na roda de conversa, como o nível do rio ideal para pescar e o quadro de pastagem. Deste modo, entende-se que os estudantes pensatam em 


\section{QUFN}

ações relacionadas a sua prática cotidiana e que seriam interessantes para discussões em sala de aula.

Este fato é primordial para o desenvolvimento de atividades de Modelagem, uma vez que os problemas são construídos e resolvidos com base na vivência dos estudantes, pois "toda cultura modela" (CALDEIRA, 2019) ${ }^{4}$, relacionando os conhecimentos científicos discutidos em sala de aula, admitindo assim, significados para a realidade e, modificando a visão desses educandos frente ao mundo que o rodeia.

Ao finalizar as análises dos dois instrumentos propostos, se vê a temáticas em destaque estão fortemente ligadas as questões culturais presentes no contexto da comunidade e da escola, o que pode facilitar a exploração dos temas em atividades curriculares, conforme os documentos norteadores da Educação do Campo no Brasil.

\section{CONCLUSÃO}

Ao finalizar esta investigação concluímos que existem muitas potencialidades que podem ser exploradas no ambiente da escola do campo, uma vez que há uma riqueza de conhecimentos neste contexto, perpassando por pelos, pelo menos, três tipos, o científico, o empírico e o religioso. Isso se justifica pois todo conhecimento é fruto de uma cultura, de um contexto e mais ainda, de relações entre membros desta cultura.

Desta forma, pode-se apontar que o ambiente destas instituições do campo é favorável para o desenvolvimento de práticas de Modelagem e, ainda, práticas que conseguem abranger diversas temáticas que estão presentes na vida e na lida do campo.

Podemos pensar que a vivência é a maior experiência que um indivíduo pode ter de um determinado contexto, é por isso que escolas do campo devem enaltecer a importância de trazer para a sala de aula do campo o próprio campo (BRASIL, 2013), pelos olhos de quem nele vive.

É nesta perspectiva que destacamos que as três temáticas identificadas se

\footnotetext{
${ }^{4}$ Informação descrita por Caldeira durante a palestra de abertura da XI Conferência Nacional de Modelagem na Educação Matemática que ocorreu na Universidade Federal de Minas Gerais, Belo Horizonte, 2019.
} 
tornam relevantes pois partem da visão dos estudantes, de como os mesmos conseguem ver o campo e a partir disto, com o auxílio da ciência, entendê-lo e modificá-lo.

\section{AGRADECIMENTOS}

O presente trabalho foi financiado pela Coordenação de Aperfeiçoamento de Pessoal de Nível Superior (CAPES). Código de financiamento 001.

\section{REFERÊNCIAS}

AUSUBEL, D. P. A aprendizagem significativa: a teoria de David Ausubel. São Paulo: Moraes, 1982.

BARDIN, L. Análise de conteúdo. Lisboa: Edições 70, 2010. 225 p.

BRASIL. Ministério da Educação. Resolução no 2, de 28 de Abril de 2008.

Disponível em: <http://portal.mec.gov.br/arquivos/pdf/resolucao_2.pdf>. Acesso em: 16 de set. de 2021.

BRASIL.Ministério da Educação. Secretaria de Educação Básica. Secretaria de Educação Continuada, Alfabetização, Diversidade e Inclusão. Conselho Nacional da Educação.Diretrizes Curriculares Nacionais Gerais da Educação Básica/ Orientações para o atendimento da Educação do Campo. Brasília: MEC, SEB, DICEI, 2013. Disponível em:125 $<$ http://portal.mec.gov.br/docman/julho-2013-pdf/13677-diretrizes-educacao-basica2013- pdf/file>. Acesso em: 16 de set. de 2021.

BLUM, W. Applications and Modelling in mathematics teaching and mathematics education - some important aspects of practice and of research. In: SLOVER, C. et. al. ADVANCES AND PERSPECTIVES IN THE TEACHING OF MATHEMATICAL MODELING AND APPLICATIONS. Yorklyn: Water Street Mathematics, 1995. p. 120. (Plenary Lecture).

CALDEIRA, A. D. Modelagem Matemática: Um novo olhar. In: ALEXANDRIA Revista de Educação em Ciência e Tecnologia. V.2, n.2, p.33-54, jul. 2009.

NETO, A. V. Currículo, cultura e sociedade. Educação Unisinos, v. 8, n. 15, p. 157$171,2004$.

SILVEIRA, R. M. G.; NADER, A. A. G.; DIAS, A. A. Subsídios para a Elaboração das Diretrizes Gerais da Educação em Direitos Humanos - versão preliminar. João Pessoa: Editora Universitária/UFPB, 2007.

THOMPSON, J. B. Ideologia e cultura moderna. Teoria social crítica na era dos meios de comunicação de massa. Petropólis: Vozes, 2009. 